\title{
Comparative Analysis of Smoking Impact on Health of Smokers and Non-Smokers of Quetta City Dwellers
}

\author{
Nelofer Jamil ${ }^{1}$, Zahoor Ahmed Bazai ${ }^{2, *}$, Musarat Riaz ${ }^{1}$, Mohsin Ali Khan ${ }^{4}$, Syeda Maria Ali ${ }^{3}$, \\ Azra Yasmin ${ }^{5}$, Uzma Jabeen ${ }^{1}$, Sabeena Rizwan ${ }^{1}$, Fazeela Mandokhel ${ }^{1}$, Ayesha Mushtaq ${ }^{1}$, Fareeda Behlil ${ }^{1}$ \\ ${ }^{1}$ Department of Chemistry, Sardar Bahadur Khan Women's University Quetta, Pakistan \\ ${ }^{2}$ Department of Botany, University of Balochistan, Pakistan \\ ${ }^{3}$ Department of Environmental Sciences, International Islamic University Islamabad, Pakistan \\ ${ }^{4}$ Department of Orthopedic Surgery, Sandeman (Provincial) Hospital, Quetta, Pakistan \\ ${ }^{5}$ Department of Environmental Sciences, Fatima Jinnah Women University, Rawalpindi, Pakistan \\ *Corresponding Author: z_bazai@yahoo.com
}

Copyright $(0) 2014$ Horizon Research Publishing All rights reserved.

\begin{abstract}
Cigarette smoking is an addictive and destructive behavior and it can cause serious health problems and most important preventable cause of death in the world. In the present study using questionnaire data of smokers ( $\mathrm{n}=$ $323)$ and non-smokers $(n=218)$ from the patients in the Out Patients Department (OPD) of civil hospital Quetta was collected. Based on smoking history, the study population was categorized into smokers $(<25$ cigarettes/day), and non-smokers while smokers were further subdivided into three sub-categories based on their ages: up to 35 , up to 50 , and above 50 . The results depicts that the mean hemoglobin $(\mathrm{Hb})$ levels of smokers and non-smokers were $15.9+0.4 \mathrm{~g} / \mathrm{L}$ and $12.6+0.5 \mathrm{~g} / \mathrm{L}$ respectively, which increased progressively with the number of cigarettes consumed per day. It was observed that $0 \%, 53.11 \%$ and 68.92 were suffering from Chest diseases in group 1, 2 and 3 respectively. In case of high blood pressure population belonging to group 1 and 2 showed greater percentage while group 3 showed lower percentage. Increase in the percentage of heart diseases with age and smoking habit was also observed in all three groups which were prominent in group 3. The present study confirms that the smoking had severe effects on health of the smokers causing lungs and heart diseases. Furthermore, the implications could be made that $60 \%$ of the total population is smokers which are the indicator in increase attitude of community towards smoking despite many initiative of declaring smoking as taboo by government and tradition of the area.
\end{abstract}

Keywords Out Patients Department (OPD),Hemoglobin, Blood Pressure, Smoking

\section{Introduction}

Cigarette smoking; becoming a major lifestyle factor is influencing the human's health1andit is an addictive and destructive behavior2. Now a days it is considered one of the serious health problems and most important preventable causes of death in world3. There are more than 4000 chemicals found in cigarette smoke4including $\mathrm{CO}$. The main source of inhaled carbon monoxide is cigarette smoking 5.It has approximately 200 fold greater affinity for haemoglobin $(\mathrm{Hb})$ as compare to oxygen6,7, resulting in the formation of carboxyhaemoglobin $(\mathrm{COHb})$. The level of $\mathrm{COHb}$ may beabove $10 \%$ in chain smokers, $4-6 \%$ range for smokers and $1-2 \%$ for non-smokers8-12. With increasing cigarette tar content and age, the absorption of relative fraction of carbon monoxide increases 13and hence the concentration of oxygen is reduced and if this happens in the body, it will eventually cause narrowing and hardening of blood vessels (atherosclerosis). Thehalf-life ( $\mathrm{t} 1 / 2)$ for $\mathrm{COHb}$ is $4-5 \mathrm{~h}$ in humans breathing air 14 .

Hemoglobin levels predict mortality and morbidity15. On average, hemoglobin decreases with age that is from 147.5 to $145.1 \mathrm{~g} / \mathrm{L} 15,16$.It is shown from some of the previous studies that increase in hemoglobin enhances mortality from heart disease 17 while on the other hand it is found by some scientists that decrease in hemoglobin is a risk factor for cardiovascular disease 18, and chronic diseases 19,20 . It is linked with many other diseases, such as respiratory diseases21. Tobacco smoke has toxic 22, genotoxic 23, mutagenic 24, and carcinogenic properties 25 .

As far as BP is concerned, cigarette smokers had lower BPs than nonsmokers which is due to their lower weight 26,27. However, nicotine present in cigarette smoke causes the blood pressure and heart rate to increase. The rise in blood pressure is due to both; an increase in cardiac output and in total peripheral vascular resistance 28.

This study explores the effect of smoking on the hemoglobin level and blood pressure. Representative population from smokers and non-smokers were randomly sampled to analyze the consequences of cigarette smoke on 
human health.

\section{Subjects and Methods}

Data collected using questionnaires already designed and developed considering different variables including $\mathrm{Hb}$, chest diseases and heart diseases. The target audiences were the patients in the OPD of civil hospital Quetta. The data was collected from the patients who visited laboratory for blood test during November 2013 to January 2014 for 90 working days and considered as 3 months. The sample size was $7.5 \%$ of the total population. Data analysis revealed that the representative population were smokers $(\mathrm{n}=323)$ and non-smokers $(\mathrm{n}=218)$ respectively. The study population ages of smokers were between 25 to 80 years and for nonsmokers 18 to 90 year for whom smoking status, Hb level, and health status were recorded. Based on smoking history, the study population was divided into two categories: smokers $(<25$ cigarettes/day), and non-smokers. Study populations were subdivided into three categories based on their ages: upto 35 , upto 50, and above 50. Hemoglobin values were tested and provided by the hospital lab.

Data was analyzed using Statistical Package for Social Sciences (SPSS) version 13. The basic statistics were applied and results were expressed in mean + standard error (S.E). The co relation between smokers and non-smoker $\mathrm{Hb}$ values were also given and linear regression results were found to be highly significant.

\section{Results}

The mean hemoglobin levels of smokers and non smokers were $15.8870 \pm 0.40277 \mathrm{~g} / \mathrm{L}$ and $12.5833 \pm 0.52345 \mathrm{~g} / \mathrm{L}$ respectively (Table1). The difference in the values of mean hemoglobin levels was not prominent within the three groups of smokers.

Table 1. Descriptive statistics for smokers and non smokers $\mathrm{Hb}$

\begin{tabular}{|c|c|c|c|c|c|}
\hline & \multicolumn{2}{|c|}{ Mean + S.E } & Min-Max & Variance & S.D \\
\hline Smoker $\mathrm{Hb}$ & \multicolumn{2}{|c|}{$15.8870+0.40277$} & $12.20-20.10$ & 3.731 & 1.93163 \\
\hline Non Smoker Hb & \multicolumn{2}{|c|}{$12.5833+0.52345$} & $8.70-15.60$ & 4.932 & 2.22082 \\
\hline \multicolumn{6}{|c|}{ One-Sample t-Test } \\
\hline & \multicolumn{5}{|c|}{ Test Value $=0$} \\
\hline & \multirow[t]{2}{*}{$\mathrm{T}$} & \multirow[t]{2}{*}{$\begin{array}{c}\text { Sig. } \\
\text { (2-tailed) }\end{array}$} & \multirow[t]{2}{*}{$\begin{array}{c}\text { Mean } \\
\text { Difference }\end{array}$} & \multicolumn{2}{|c|}{$\begin{array}{l}95 \% \text { Confidence Interval of the } \\
\text { Difference }\end{array}$} \\
\hline & & & & Lower & Upper \\
\hline smokerHb & 39.444 & .000 & 15.88696 & 15.0517 & 16.7223 \\
\hline NsmokerHb & 24.039 & .000 & 12.58333 & 11.4789 & 13.6877 \\
\hline
\end{tabular}


It was observed that $0 \%$ population of group 1 was suffering from TB and COPD while in group $2,46.89 \%$ population was safe from the chest diseases \& $53.11 \%$ population was suffering from TB for three years (fig. 1). In group 3, 31.08\% population was found safe from chest diseases while $39.38 \%$ and $29.54 \%$ were suffering from TB and COPD respectively (fig. 2).

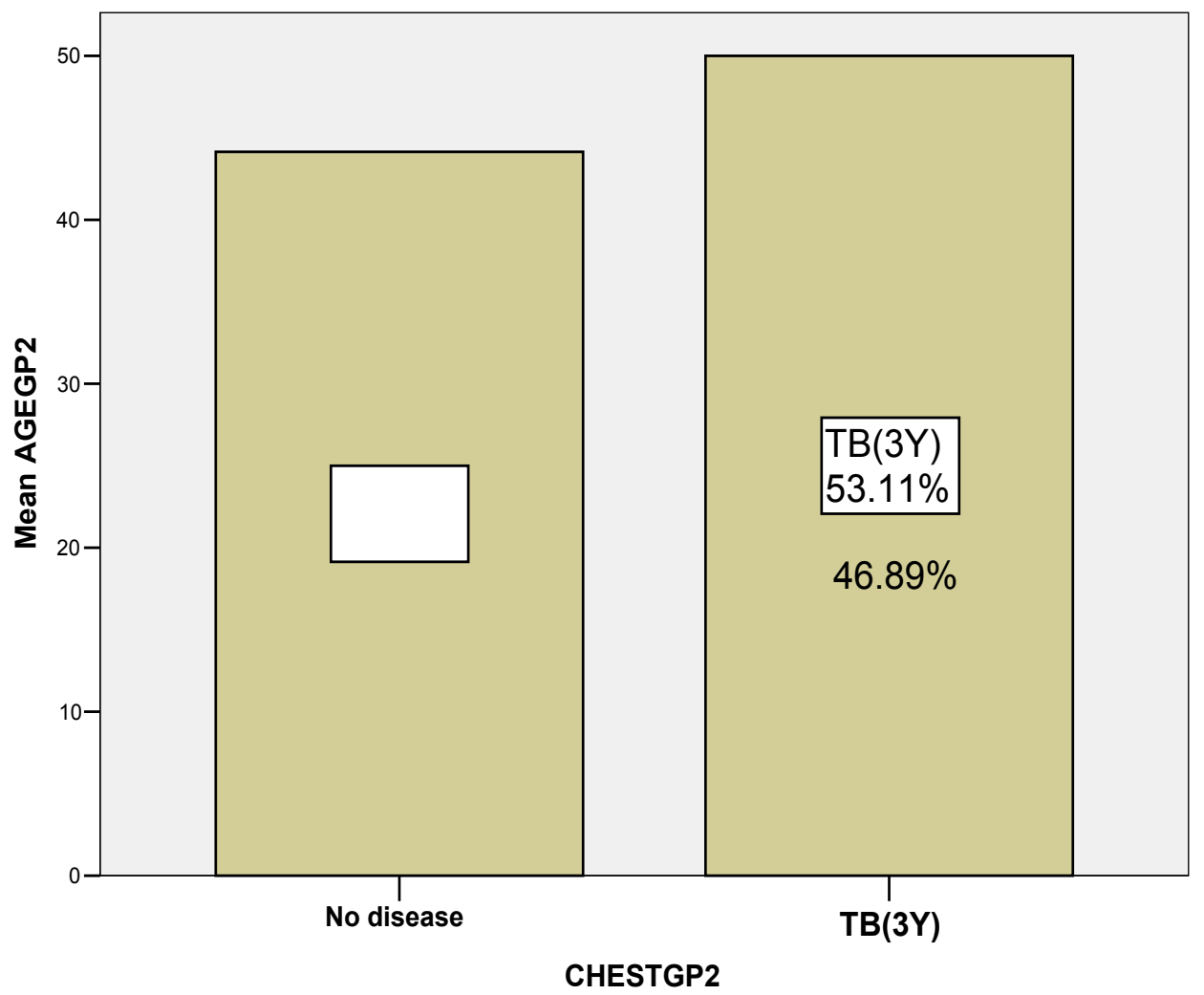

Figure1. Percentage of population suffering from chest diseases in group 2 with respect to age.



Figure2. Percentage of population suffering from chest diseases in group 3 with respect to age.

Population belonging to group 1 and 2 showed greater percentage of high blood pressure than normal i.e $66.67 \%$ and $62.5 \%$ 
respectively (fig. 3 \& 4). On the other hand, results of group 3 showed lower percentage of high blood pressure that is $33.33 \%$ (fig. 5)

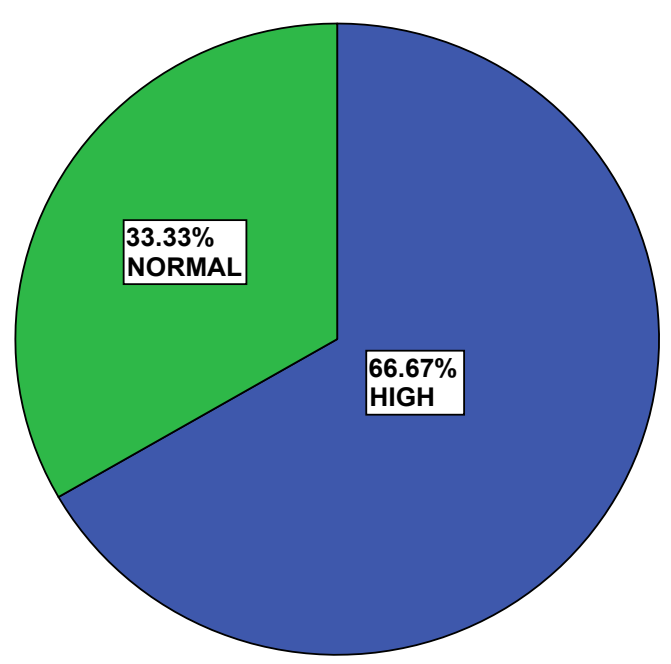

Figure3. Percentage of population showing high and normal blood pressure in group 1

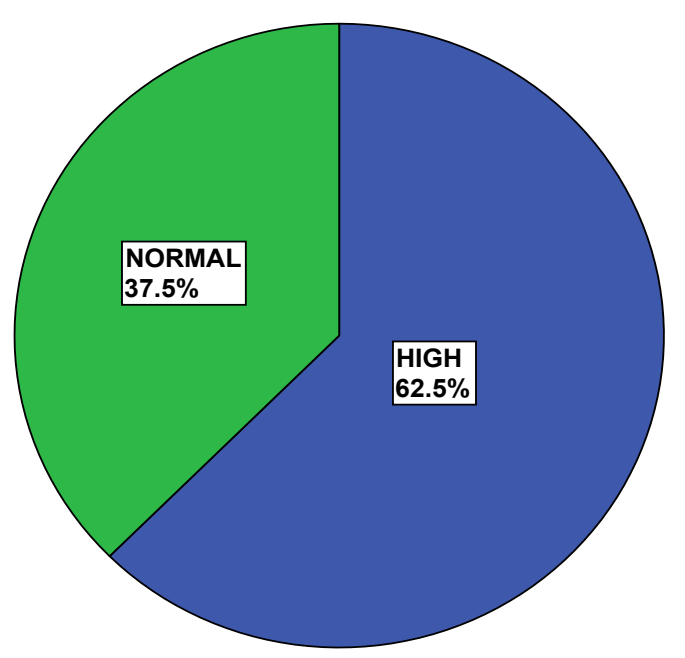

Figure 4. Percentage of population showing high and normal blood pressure in group 2

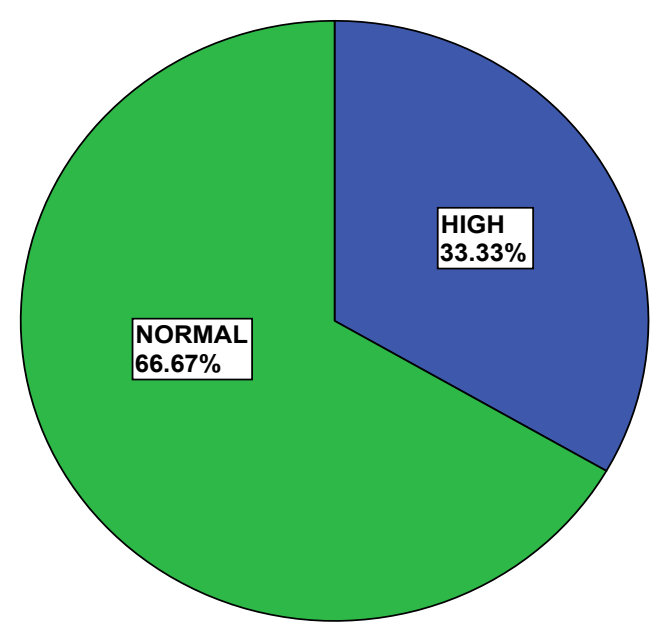

Figure 5. Percentage of population showing high and normal blood pressure in group 3 


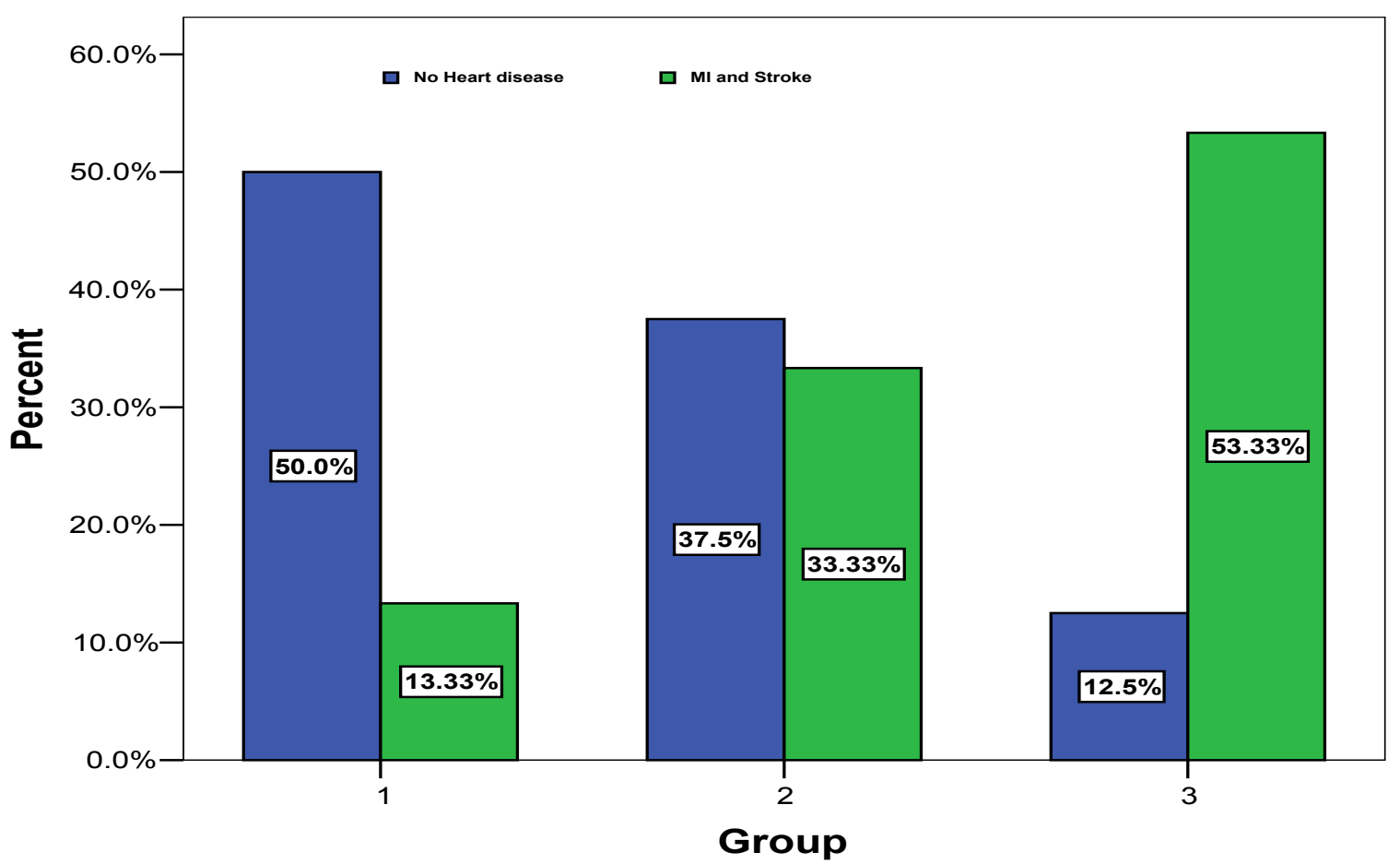

Figure 6. Percentage of population showing heart diseases.

Table 2. Linear regression results for three groups of smokers.

\begin{tabular}{cccc}
\hline & R value & Mean square & F \\
\hline Group 1 & 0.642 & 3.308 & 2.799 \\
Group 2 & 0.1 & 0.184 & 0.06 \\
Group 3 & $0.688^{*}$ & 22.22 & 6.288 \\
\hline
\end{tabular}

* value significant at $\mathrm{p}<0.05$

Population belonging to group 1, 2 and 3 showed increase in the percentage of heart diseases with age respectively (fig. 6). About $68.88 \%$ population of group 3 were affected with increase in the number of cigarettes per day and age. Linear regression showed that the increase in heart diseases with age and period of smoking are highly significant at $p<0.05$ for group 3only while for group 1 and 2 it is non-significant (Table 2).

\section{Discussion}

The trend of smoking is increasing day by day in all age groups. The increase in the number of cigarette per day is the cause and severity of different diseases. Our results indicated an increase in the hemoglobin with the number of cigarettes consumed per day. These results are in broad agreement with other studies who also reported that the increase in the number of cigarettes increases blood levels of carboxyhemoglobin and carbon monoxide which causes the blood to be thickened and hence may increase blood pressure and the risk of coronary heart disease $5,15,29,30$.

Cigarette smoking is the major risk factor of COPD and also of all chronic diseases and cancer ${ }^{33,34}$. The respiratory system is mostly harmed by tobacco smoke ${ }^{31,32}$. Our data showed that respiratory diseases are prominent in the second and third group. These results are highly supported by the findings of Rabe indicating that in any smoker aged $>40 \mathrm{yrs}$ COPD should be considered with other symptoms ${ }^{35}$.

Our data also indicated the reduction in the percentage of high BP patients in group 3. These findings are supported by Omvik who proposed that due to the presence of nicotine in cigarette tobacco blood pressure and heart beat is likely to increase during smoking ${ }^{28}$. However, in several studies, smokers tend to have a slightly lower blood pressure than non-smokers ${ }^{36}$.

Several mechanisms may intensify the risk of coronary heart disease in persons exposed to tobacco smoke. Our results also indicated that the risk of heart diseases for smoker's increases with age and habit of smoking that is number of cigarettes consumed per day and these result are highly correlated with the findings of other researcher too ${ }^{17}$, 28,37 . There is always a possibility of some cultural factors such as nature of housing, time spent in office and outside home and also the diet habits which are not measured and may be considered in future research. 


\section{Conclusion and Recommendations}

The present study confirms that the smoking had severe effects on health of the smokers causing lungs and heart diseases. Furthermore, the implications could be made that $60 \%$ of the total population is smokers which are the indicator in increase attitude of community towards smoking despite many initiative of declaring smoking as taboo by government and tradition of the area.

\section{REFERENCES}

[1] Padmavathi P, Reddy V D, Kavitha G, Paramahamsa M, Varadacharyulu N. Chronic cigarette smoking alters erythrocyte membrane lipid composition and properties in male human volunteers. Nitric Oxide, 2010; 23:181-186.

[2] Krannitz Kristopher W., DPM,Hon W. Fong, DPM,Lawrence M. Fallat, DPM, FACFAS, and John Kish. The Effect of Cigarette Smoking on Radiographic Bone Healing After Elective Foot Surgery,. The journal of foot \& ankle surgery, 2009; 48(5).

[3] Jha P, Jacob B, Gajalakshmi V, Gupta PC, Dhingra N, Kumar $\mathrm{R}$, et al. A nationally representative case-control study of smoking and death in India. N Engl JMed 2008; 358: 113747.

[4] Green CR, Rodgman A. The Tobacco Chemists' Research Conference: a half century forum for advances in analytical methodology of tobacco and its products. Recent Adv Tobacco Sci 1996; 22: 131-304.

[5] Nordenberg D, Yip R, Binkin NJ. The effect of cigarette smoking on hemoglobin levels and anemia screening. J Am Med Assoc 1990;264:1556-9.

[6] Haab P. The effect of carbon monoxide on respiration. Experientia 1990; 46: 1202-6.

[7] Salhany JM. Effect of carbon dioxide on human hemoglobin. Kinetic basis for the reduced oxygen affinity. J Biol Chem 1972; 247: 3799-801.

[8] Ayres SM, Giannelli SJ, Armstrong RG. Carboxyhemoglobin: hemodynamic and respiratory responses to small concentrations. Science 1965;149:193-4

[9] Goldsmith JR. Contribution of motor vehicle exhaust, industry, and cigarette smoking to community carbon monoxide exposures. Ann N Y Acad Sci 1970;174:122-34.

[10] Overgaard J, Nielsen JE, Grau C. Effect of carboxyhemoglobin on tumor oxygen unloading capacity in patients with squamous cell carcinoma of the head and neck. Int J Radiat Oncol Biol Phys 1992; 22:407-10.

[11] Stewart RD, Baretta ED, Platte LR, et al. Carboxyhemoglobin levels in American blood donors. J Am Med Assoc 1974;229:1187-95

[12] Turner JA, McNicol MW, Sillett RW. Distribution of carboxyhaemoglobin concentrations in smokers and non-smokers. Thorax 1986; 41:25-7.

[13] Cronenberger.C, Diane R. Mould, Hans-Juergen Roethig1 \&
Mohamadi Sarkar1 Population pharmacokinetic analysis of carboxyhaemoglobin concentrations in adult cigarette smokers British Journal of Clinical PharmacologyDOI:10.1111/j.1365-2125.2007.02974.x

[14] Stewart RD. The effects of low concentration of carbon monoxide in man. Scand J Respir Dis Suppl 1974;91:56-62.

[15] Skjelbakken T, Inger Marie S. Dahl, Wilsgaard T, Langbakk $\mathrm{B}$ and Maja-Lisa Lochen. Changes in haemoglobin levels according to changes in body mass index and smoking habits, a 20-year follow-up of a male cohort Tlze Tromso Study 19 74-1995. European Journal of Epidemiology Cardiovascular Diseases, 2006; 21: 493-499.

[16] 16. Skjelbakken.T, Inger Marie S. Dahl, and Maja-Lisa Løchen. Changes in Body Mass Index and Smoking Habits Have a Different Impact on Hemoglobin Concentration in Men and Women: A Longitudinal Follow-Up of the Tromsø Study, 1994-2002. Gender Medicine/Vol. 7, NO. 3, 2010

[17] Carlson LA, Bottiger LE. Risk factors for ischaemic heart disease in men and women. Results of the 19-year follow-up of the Stockholm Prospective Study. Acta Med Scand 1985; 218: 207-211.

[18] Sarnak MJ, Tighiouart H, Manjunath G, et al. Anemia as a risk factor for cardiovascular disease in The Ath erosclerosis Risk in Communities (ARIC) study. J Am Coll Cardiol 2002; 40: 27-33.

[19] Salive ME, Cornoni HJ, Guralnik JM, et al. Anemia and hemoglobin levels in older persons: Relationship with age, gender, and health status. J Am Geriatr Soc 1992; 40: 489-496.

[20] Bentley DP. Anaemia and chronic disease. Clin Hae matol $1982 ; 11: 465-479$

[21] Report by the Surgeon General. The Health Consequences of Smoking. Executive Summary: A Report of the Surgen General. Washington, DC: U.S. Public Health Services 2004.

[22] Stohs, S. J., Bagchi, D., \& Bagchi, M. Toxicity of trace elements in tobacco smoke. Inhalation Toxicology, 1997;9: 867-890.

[23] Husgavfel-Pursiainen, K. Genotoxicity of environmental tobacco smoke: A review. Mutation Research, 2004;567: 427-445.

[24] Demarini, D. M. Genotoxicity of tobacco smoke and tobacco smoke condensate: A review. MutationResearch,2004; 567: 447-474.

[25] Eyre, H., Kahn, R., Robertson, R. M., Clark, N. G., Doyle, C., Gansler, T., et al.. Preventing cancer, cardiovascular disease, and diabetes: A common agenda for the American Cancer Society, the American Diabetes Association, and the American Heart Association. CA: A Cancer Journal For Clinicians, 2004; 54: 190-207.

[26] Gordon T, Kannel W B. MD Drinking and Its Relation to Smoking, BP, Blood Lipids, and Uric AcidThe Framingham Study Arch Intern Med. 1983;143(7):1366-1374.

[27] Handa. K, Tanaka H, Shindo M, Kono S, Sasaki J, Arakawa K. Relationship of cigarette smoking to blood pressure and serum lipids. Atherosclerosis, 1990; 84( 2) : 189-193.

[28] Omvik P. How smoking affects blood pressure. Blood Press, 1996; 5(2):71-7. 
[29] Natvig H. Studies on hemoglobin values in Norway. I. Hemoglobin levels in adults. Acta Med Scand. $1963 ; 173: 423-434$.

[30] Yip R, Johnson C, Dallman PR. Age-related changes in laboratory values used in the diagnosis of anemia and iron deficiency. Am J Clin Nutr. 1984;39: 427-436.

[31] Zhang H, Cai B. The impact of tobacco on lung health in China. Respirology. 2003 Mar;8(1):17-21.

[32] Unverdorben M, Mostert A, Munjal S, van der Bijl A, Potgieter L, Venter C, Liang Q,

[33] Meyer B, Roethig H J. Acute effects of cigarette smoking on pulmonary function. Regulatory Toxicology and Pharmacology, 2010; 57: 241-246

[34] Ezzati M, Lopez AD. Estimates of global mortality attributable to smoking in 2000. Lancet 2003; 362: 847-852.
[35] Mannino DM, Davis KJ. Lung function decline and outcomes in an elderly population. Thorax 2006; 61: 472-477.

[36] Rabe KF, Hurd S, Anzueto A, et al. Global Strategy for the diagnosis, management, and prevention of COPD: GOLD executive summary. Am J Respir Crit Care Med 2007; 176: $532-555$.

[37] Bang LE, Buttenschøn L, Kristensen KS, Svendsen TL. Do we undertreat hypertensive smokers? A comparison between smoking and non-smoking hypertensives. Blood Press Monit, 2000;5(5-6):271-4.

[38] Goya W, Gordon D.O. L, Gerald S, Ann R, Lucy L and Peter H. Whincup. Associations between cigarette smoking, pipe/cigar smoking, and smoking cessation, and haemostatic and inflammatory markers for cardiovascular disease. European Heart Journal, 2005; 26, 1765-1773. 